\title{
DIAGNÓSTICO DA PRODUÇÃO E COMERCIALIZAÇÃO TRANSFRONTEIRIÇA DE HORTALIÇAS NA FRONTEIRA ENTRE OS MUNICÍPIOS DE CORUMBÁ E LADÁRIO NO BRASIL E PUERTO QUIJARRO E PUERTO SUAREZ NA BOLÍVIA.
}

\author{
DIAGNOSIS OF CROSS-BORDER TRADE AND PRODUCTION OF VEGETABLES
}

BETWEEN THE MUNICIPALITIES OF CORUMBÁ AND LADARIO IN BRAZIL AND

PUERTO QUIJARRO AND PUERTO SUAREZ IN BOLIVIA.

\author{
Alberto Feiden ${ }^{1}$ \\ Edgar Aparecido da Costa ${ }^{2}$
}

\section{Grupo de Trabalho: AGROECOLOGIA}

\begin{abstract}
Resumo
O presente trabalho teve como objetivo levantar informações bem como sistematizar as informações existentes sobre as condições de produção e comercialização de hortaliças no Arranjo Populacional de Fronteira de Corumbá entre o Brasil e a Bolívia, com o objetivo de subsidiar políticas públicas específicas para a região de fronteira. Foi feito um levantamento dos principais eventos que impactaram o abastecimento alimentar da população do arranjo nos meios de comunicação. Com a ferramenta Google Earth foram feitos mapas para ilustrar a localização, o fluxo e as cadeias de abastecimento do arranjo. Foi aplicado um questionário rápido aos principais feirantes da feira de Corumbá, entre os que vendem hortifrutigranjeiros e os que comercializam grãos. Os resultados mostram uma grande interdependência entre as populações locais do Brasil e da Bolívia em relação ao abastecimento e segurança alimentar, devido ao isolamento das comunidades do restante dos dois países. É necessário e urgente discutir a regularização do intercambio na fronteira, mas essa regularização exige novos marcos legais específicos para situações de fronteira, pois não é possível dentro dos marcos atuais.
\end{abstract}

Palavras-chave: agricultura familiar, feiras, comercio internacional,

\footnotetext{
${ }^{1}$ Embrapa Pantanal - Programa de Pós Graduação em Desenvolvimento Rural Sustentável - Mestrado e Doutorado - Unioeste - Campus de Marechal Cândido Rondon, Engenheiro Agrônomo, Dr em Agronomia, afeiden@yahoo.com.br

${ }^{2}$ Universidade Federal do Mato Grosso do Sul, Campus Pantanal, Geógrafo, Dr. Em Geografia, edgarac10@gmail.com
} 


\section{SEMINÁRIO INTERNACIONAL DE PÓS GRADUAÇĀ̃ EM DESENVDLVIMENTO RURAL SUSTENTÁVEL IV JORNADA QUESTÄO AGRÁRIA E DESENVOLVIMENTO \\ INTERDISCIPLINARIDADE E DESENVIVIIMENTO RURAL SUSTENTÁvel. \\ UNIOESTE - MARECHAL CÂNDIDO RONDON - PR \\ 22 A 25 DE NOVBMBRO DE 2017}

\section{Abstract}

The present study aims to obtain and systematize the information about the conditions of production and trade of vegetables in the Populational Frontier Arrangement de Corumbá between Brazil and Bolivia. The goal is to help elaborate specific public policies for the border region. A research was made on the means of electronic communication to detect events that impacted the food supply of the arrangement. Using the Google Earth were made maps to illustrate the location, the flow and supply chains of the arrangement. A fast questionnaire was applied to the main sellers of Corumba's local market between those who sell vegetables and grain. The results show a great interdependence between local populations from Brazil and Bolivia in relation to the food supply and food security, due to the isolation of the rest of the two countries. There is an urgent need to discuss the regularisation of the international trade at the border. This adjustment, however, requires new legal dispositions that are specific to frontier situations, which is not possible within the current legal marks.

Key words: family farming, local market, international trade.

\section{INTRODUÇÃO}

Os municípios brasileiros de Corumbá e Ladário junto com os municípios bolivianos de Puerto Quijarro e Puerto Suarez, são entidades relativamente isoladas geográficamente e por isso tem um intenso intercambio cultural, turístico, comercial e de pessoas.

Conforme IBGE (2016) os quatro municípios formam um Arranjo Populacional de Fronteira, sendo o quarto entre os 27 Arranjos Populacionais de Fronteira do Brasil em termos de população, sendo superados apenas pelos arranjos Internacionais de Foz do Iguaçu-Ciudad del Este no Paraná; Pedro Juan Caballero-Ponta Porã no Mato Grosso do Sul e Santana do Livramento-Rivera no Rio Grande do Sul. Segundo a mesma fonte, os 27 arranjos populacionais nas fronteiras internacionais do Brasil envolvem uma população de 2.081.629 habitantes, sendo $55,8 \%$ de brasileiros e $44,2 \%$ de habitantes de países vizinhos. O Mato Grosso do Sul é o segundo estado brasileiro em aglomerações, possuindo cinco arranjos. Brasil e Bolívia compartilham mais dois arranjos além do arranjo local: Cobija-Brasileia no Acre e Guajará Mirim-Guayará Merin em Rondônia.

O Arranjo estudado possui 150.000 habitantes dos quais 123.000 residem no Brasil e 28.000 são moradores da Bolívia (IBGE, 2016). Essa população está assim distribuída: Corumbá, 103.707 habitantes (68 \%); Ladário, 19.617 habitantes (19\%); Puerto Suarez, 15.209 (10\%) e Puerto Quijarro 12.903 (9\%). 


\section{SEMINÁRIO INTERNACIONAL DE PÓS GRADUAÇĀO EM DESENVDLVIMENTO RURAL SUSTENTÁVEL IV JORNADA QUESTÄO AGRÁRIA E DESENVOLVIMENTO \\ INTERDISCIPLINARIDADE E DESENVIVIIMENTO RURal SUSTENTÁvel. \\ UNIOESTE - MARECHAL CÂNDIDO RONDON - PR \\ 22 A 25 DE NOVBMBRO DE 2017}

Conforme revisão feita por Souza (2010), a Cidade de Corumbá foi fundada em 1778 com o objetivo de garantir a posse do território e deter o avanço da forças espanholas, já que o ponto era estratégico para o acesso às minas de Cuiabá. A partir de então a cidade polo da região passou por diferentes fases de desenvolvimento, sendo a primeira como centro estratégico geográfico e militar. A partir da instalação do porto em 1853, passa a assumir um papel estratégico na comunicação e comércio com as cidades platinas e a Europa, atividade que foi interrompida de 1865 a 1867 pela ocupação da cidade pelas tropas paraguaias durante a Guerra do Paraguai.

A época de ouro de Corumbá ocorre após a guerra do Paraguai até a chegada da ferrovia Noroeste do Brasil (NOB) a Porto Esperança em 1914, a partir do qual a importância do porto passa decair (SOUZA, 2010). É neste período antes da chegada da ferrovia que Corumbá se torna importante entreposto comercial na bacia Plantina chegando a ser o terceiro porto fluvial do país. A chegada da ferrovia a Corumbá em 1952 (CORRÊA, 2012), reduz ainda mais importância da navegação, sendo que a partir desta época a cidade entra em decadência, que é agravado pela implantação do sistema rodoviário, onde Campo Grande passa a assumir o principal papel no então sul do Mato Grosso, tanto que assume a função de capital no momento da criação do estado do Mato Grosso do Sul (SOUZA, 2010). A partir daí a cidade, que já fora a maior metrópole e a cidade mais cosmopolita do antigo estado do Mato Grosso, se reduz a ponto de passagem de produtos para a Bolívia (ITO, 2000, apud SOUZA 2010). Atualmente a cidade funciona como importante centro de intercambio comercial entre o Brasil e o Oriente Boliviano, principalmente o Departamento de Santa Cruz, com intenso fluxo de mercadorias tanto por via rodoviária, como ferroviária e fluvial, bem como fluxo de pessoas, tanto bolivianos que buscam trabalho no Brasil, como brasileiros em busca de terras na Bolívia (SOUZA, 2010).

Do lado Boliviano, Puerto Suarez foi fundada em 1875 (SOUZA, 2010), e Puerto Pacheco foi fundada em 1885, sendo que em 1905 soldados camponeses ocuparam áreas rurais muito próximas ao limite internacional com o Brasil, criando as colonias de El Carmen de la Frontera e San Pedrito. Desde a fundação destas duas comunidades se reforçou a integração entre os dois povos, sendo que muitos bolivianos passaram a trabalhar em fazendas e empresas brasileiras (COSTA, 2013, apud CUYATE, 2015). Puerto Surez fica a cerca de 15 $\mathrm{km}$ de Corumbá, sendo importante polo de infraestrutura modal composto por rodovia que liga a Corumbá e a Santa Cruz de La Sierra, como pela estrada de Ferro Santa Cruz de La 
Sierra-Puerto-Suarez-Puerto-Quijarro-Corumbá, e importante complexo portuário, através da Laguna Cáceres e através de Puerto Quijarro pelo canal do Tamengo tem acesso ao Rio Paraguai (MAX, 2008 apud SOUZA, 2010).

O potencial econômico de ambos os lados da fronteira se baseia na pecuária, mineração, turismo e comércio, principalmente o intercâmbio internacional de mercadorias entre o Brasil e a Bolívia (COSTA, et al, 2009).

Um dos espaços de integração mais importantes e característicos na atualidade são as feiras livres, que ocorrem de domingo às segundas-feiras distribuídas pelos bairros das cidades de Corumbá e Ladário. Estas feiras livres são territórios de integração entre brasileiros e bolivianos, ponto de encontro entre o urbano e o rural, além da função comercial de abastecimento com produtos como hortaliças, mandioca, abóbora, quiabo, maxixe, rapaduras de vários sabores e doces de frutas, além de frutas como melão caipira, mamão, ata, bocaiuva, acerola, manga, além de leite, queijo e mel, são produzidas nos assentamentos desses municípios (COSTA et. al, 2009), pelos agricultores do lado boliviano ou mesmo de produtos que percorrem uma longa cadeia logística e que são revendidos pelos feirantes dos dois países.

\footnotetext{
"Os produtos se destacam nas barracas pela sua organização, pelo seu colorido. Entres as barracas que chamam mais atenção, pelo seu colorido, estão as de hortaliças, legumes e frutas e as barracas de temperos e especiarias que normalmente são acondicionados em sacos de linha e vendidos a granel. Alguns feirantes modernizaram o acondicionamento de seus produtos, pois são vendidos em pequenas porções em sacos plásticos vedados. Outro destaque é a vestimenta das feirantes bolivianas com suas tranças, chapéu e fartas saias. Também o que não deixa de ser notado entre consumidores brasileiros e feirantes bolivianos e entre esses e feirantes brasileiros é o contato de duas linguas distintas: português e espanhol. Nessa relação de compra e venda entre povos diferentes as línguas se misturam e surge o "portunhol" (COSTA et. al, 2009)".
}

Segundo Costa et. al. (2009) a feira de um importante espaço de integração entre brasileiros e bolivianos, mesmo com algumas disputas por espaços. Há uma intensa troca nos aspectos sociais, culturais, econômicos e ambientais entre os dois povos. Também Cuyate (2015) se referindo às feiras e Ladário considera que "também são lugares de sociabilidade, porque os frequentadores interagem entre si e com os feirantes, fazendo novas amizades, reencontrando "velhos" amigos". 


\section{SEMINÁRIO INTERNACIONAL DE PÓS GRADUAÇÄO EM DESENVDLVIMENTO RURAL SUSTENTÁVEL IV JORNADA QUESTÄO AGRÁRIA E DESENVOLVIMENTO \\ INTERDISCIPLINARIDADE E DESENVIVIIMENTO RURal SUSTENTÁvel. \\ UNIOESTE - MARECHAL CÂNDIDO RONDON - PR \\ 22 A 25 DE NOVBMBRO DE 2017}

No entanto o cenário das feiras livres de Corumbá e Ladário não é apenas um espaço idílico de integração, pois conforme diferentes autores (FEIDEN et. al, 2007; COSTA et. al., 2008 e 2009, SOUZA 2010, CUYATE, 2015) ocorrem tensões entre os feirantes bolivianos, os feirantes e agricultores dos assentamentos rurais, os consumidores e os fiscais da prefeitura municipal, uma vez que entre os feirantes dos dois países ocorrem disputas por espaços, por lugares, preços, mercadorias e clientes.

De acordo com Souza (2010) e Cuyate (2015) os agricultores brasileiros estariam em desvantagem em relação aos bolivianos na comercialização de hortaliças, porque segundo os autores, os insumos na Bolívia são mais baratos no Brasil e por isso os camponeses assentados do lado brasileiro perdem em capacidade competitiva, embora reconheçam que isto representa vantagem para os consumidores.

Segundo Cuyate (2015) o fato de não haver preferencia significativa entre os consumidores pela nacionalidade dos feirantes de quem compram os produtos, sendo que (52\% preferem bolivianos e $48 \%$ preferem os brasileiros) e que o principal motivo da preferência $(54,81 \%)$ é o preço, seguido pela qualidade $(14,42 \%)$, pela confiança $(12,50 \%)$, pela tradição $(10,58 \%)$ e pela amizade $(7,69 \%)$, também coloca os agricultores e feirantes brasileiros em desvantagem.

Conforme Souza (2010), o desenvolvimento da produção de hortaliças nos municípios bolivianos se deu a partir do final dos anos 1970 e início dos 1980, constatado tanto por fontes bibliográficas como por entrevistas aos agricultores. Já segundo Roese, (2003) a produção de hortaliças na Bolívia é praticada em pequenas parcelas, de um a dois hectares, na maioria das vezes no sistema de parceria ("meeiros") ou arrendadas, com metade da produção ou do valor desta destinada ao proprietário da terra. O autor identificou cerca de 50 agricultores urbanos no Município de Puerto Suarez, produzindo para as feiras livres de Corumbá e Ladário.

No município de Corumbá, a produção de hortaliças, principalmente folhosas, era feita por cerca de 30 agricultores urbanos cuja produção era vendida na própria horta e nos sacolões (FEIDEN et al., 2007). A partir de 2010, com a implementação de politicas públicas como o Programa de Aquisição de Alimentos do Governo Federal (PAA) e o Programa Nacional de Alimentação Escolar, (PNAE) com aquisição de produtos da Agricultura Familiar, estimulou os agricultores dos assentamentos a entrarem na produção de hortaliças, e como estes tem áreas maiores disponíveis e menores custos de água. Como os agricultores urbanos utilizavam água da concessionária pública, isto implicava em custos de produção 
mais elevados que para os assentados, sendo que apesar da proximidade do mercado, os agricultores urbanos não conseguiram competir com os agricultores assentados. Além disso, com a dinamização da economia, vários agricultores perderam suas áreas, que foram retomadas pelos proprietários para construção.

Apesar da vantagem competitiva dos agricultores assentados na borda oeste do Pantanal sobre os agricultores urbanos de Corumbá, as condições de produção dos mesmos também não são as ideais. Os solos, embora tenham boa fertilidade natural, possuem limitações físicas causadas por suas características de endurecimento, aderência e fendilhamento no caso dos Vertissolos, enquanto que nas outras classes de solo encontradas ocorrem situações de pouca profundidade efetiva e presença de afloramentos rochosos na superfície, tornando-os difíceis para serem manejados e utilizados com agricultura nos padrões convencionais (SPERA et. al., 1997). Estudos mostram que a maioria dos assentados $(68,5 \%)$ considera os solos bons, sendo que $81,1 \%$ não utilizam adubação em suas lavouras. Dos assentados que fazem adubação $81,8 \%$ usam somente adubação orgânica (CAMPOLIN et al 2010). Outras restrições ao desenvolvimento integrado dessa área dizem respeito às lavouras são as condições climáticas, marcadas por um período anual entre quatro a nove meses de seca extrema (SORIANO, 1977). Além disso, o acesso à água é muito limitado ocorrendo deficiência mesmo para consumo humano, tanto em quantidade quanto em qualidade. A distribuição nos assentamentos é feita a partir de poços comunitários, sem tratamento. Além disso a água disponível contem altos teores de sais, com dominância de Carbonato de Cálcio (água dura), embora existam poços com altos teores de outros sais (CAMPOLIN; FEIDEN; LISITA, 2016).

O presente trabalho teve como objetivo levantar informações bem como sistematizar as informações existentes sobre as condições de produção e comercialização de hortaliças no Arranjo Populacional de Fronteira de Corumbá entre o Brasil e a Bolívia, englobando os municípios de Corumbá e Ladário no Brasil e Puerto Quijarro e Puerto Suarez na Bolívia, para subsidiar políticas públicas específicas para a região de fronteira, que permitam legalizar e disciplinar os fluxos de produtos alimentícios entre os dois países, para atender as feiras de Corumbá e Ladário, bem como garantir a segurança alimentar da população dos dois lados da fronteira. 
Além disso estes dados visam subsidiar a equipe para apoio ao processo de transição agroecológica com a qual está atuando desde 2011 e servir de argumentos para a implantação do processo de transição agroecológica na Bolívia, que está em negociação com parceiros bolivianos.

\section{METODOLOGIA.}

Foi feita uma revisão bibliográfica dos estudos relativos à produção e comercialização de hortaliças nas feiras para levantar as informações já existentes sobre o tema. Foi feito um levantamento dos principais eventos que impactaram o abastecimento alimentar da população do arranjo nos meios de comunicação.

Utilizando a ferramenta Google Earth foram elaborados mapas a partir das imagens da ferramenta, para ilustrar a localização e o isolamento do Arranjo bem como o fluxo e as cadeias de abastecimento.

Para entender a procedência dos produtos vendidos na feira foi aplicado um questionário curto e rápido aos principais feirantes bolivianos de Corumbá, escolhidos pela sua diversidade de produtos. Entre eles foram entrevistados oito feirantes que vendem hortifrutigranjeiros e os cinco principais que comercializam grãos. Os dados foram analisados em matriz simples e como praticamente não houve diferença nas respostas não foi feito outro tipo de análise. Para entender os sistemas de produção no lado boliviano, foi feita uma discussão grupal com os participantes de duas associações de produtores de Puerto Suarez por ocasião de duas capacitações conjuntas entre a Embrapa Pantanal e a SEDACRUZ (Servicio Departamental Agropecuario de Sanidad e Inocuidad Agroalimentaria de Santa Cruz) e FTE (Fundacion Trabajo Empresa). Para caracterização da produção dos assentamentos de Corumbá e Ladário, bem como da agricultura urbana de Corumbá foram utilizadas informações de estudos anteriores feitos pela equipe. 


\section{RESULTADOS E DISCUSSÃO.}

Para o Instituto Brasileiro de Geografia e Estatística, ARRANJOS POPULACIONAIS são "Agrupamento de municípios onde há uma forte integração populacional devido aos movimentos pendulares para trabalho ou estudo, ou à contiguidade entre as manchas urbanizadas principais" (IBGE, 2016). Quando estes arranjos englobam municípios de fronteira, envolvendo populações de mais de um país, estes passam a ser chamados de Arranjos Populacionais de Fronteira. A Figura 1 mostra uma imagem do Google Earth com o Arranjo Populacional de Corumbá, na fronteira do Brasil com a Bolívia englobando os municípios de Corumbá e Ladário no Brasil e de Puerto Quijarro e Puerto Suarez na Bolívia.

A linha amarela mostra a fronteira entre os dois países, sendo que a partir de Puerto Suarez (à esquerda) para Corumbá (à direita) pode se observar a Baia de Cáceres, o Canal do Tamengo lingando a Baía ao Rio Paraguai. O Canal do Tamengo atualmente é a única ligação da Bolívia ao Oceano Atlântico, e pela hidrovia dos rios Paraguai-Paraná, chega San Nicolás, próximo a Buenos Aires, onde ocorre o trasbordo para navios oceânicos.

Figura 1: Arranjo Populacional de Fronteira de Corumbá.

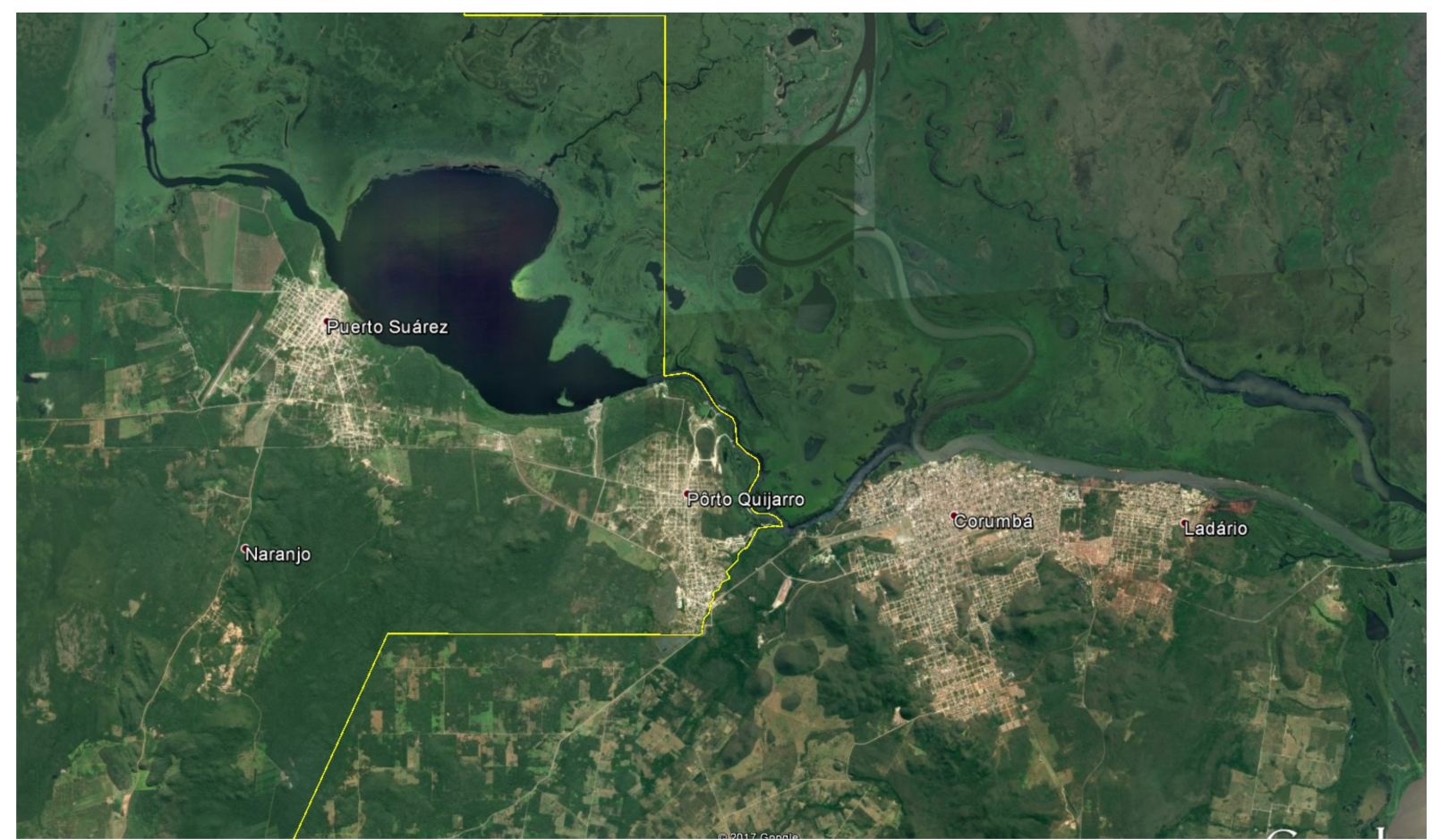


Este Arranjo é o $4^{\circ}$ arranjo Brasileiro em População, sendo o segundo do estado do Mato Grosso do Sul e o primeiro da Bolívia com Brasil. São 150.000 habitantes dos quais 123.000 no Brasil e 28.000 na Bolívia (IBGE, 2016). A Característica principal desse arranjo é seu isolamento: Pela rodovia, Corumbá fica a $220 \mathrm{~km}$ de Miranda, primeira cidade brasileira após o Pantanal. Já Puerto Suarez, também por rodovia, fica a $233 \mathrm{~km}$ de Roboré, primeira cidade com porte razoável na Bolívia, embora tenha pequenas comunidades mais próximas como El Carmen Rivero Torres a 92 km, como mostra a Figura 2.

Mas nem Miranda nem Roboré são fontes de abastecimento para os quatro municípios, pois o abastecimento de Corumbá e Ladário depende da capital do estado, Campo Grande que fica a $430 \mathrm{~km}$. Por outro lado, o abastecimento de Puerto Suarez e Puerto Quijarro dependem da capital departamental, Santa Cruz de La Sierra que fica a $640 \mathrm{~km}$ conforme mostra a Figura 3. No entanto mesmo estas cidades funcionam apenas como entrepostos de abastecimento. Conforme informações pessoais da equipe da FTE da Bolívia, a produção de hortaliças que abastece os entrepostos de Santa Cruz de La Sierra é feita nos Valles Cruceños, na Província Florida, em especial do município de Pampa Grande.

Figura 2: Localização do Arranjo Populacional de Fronteira de Corumbá, em relação às cidades mais próximas.

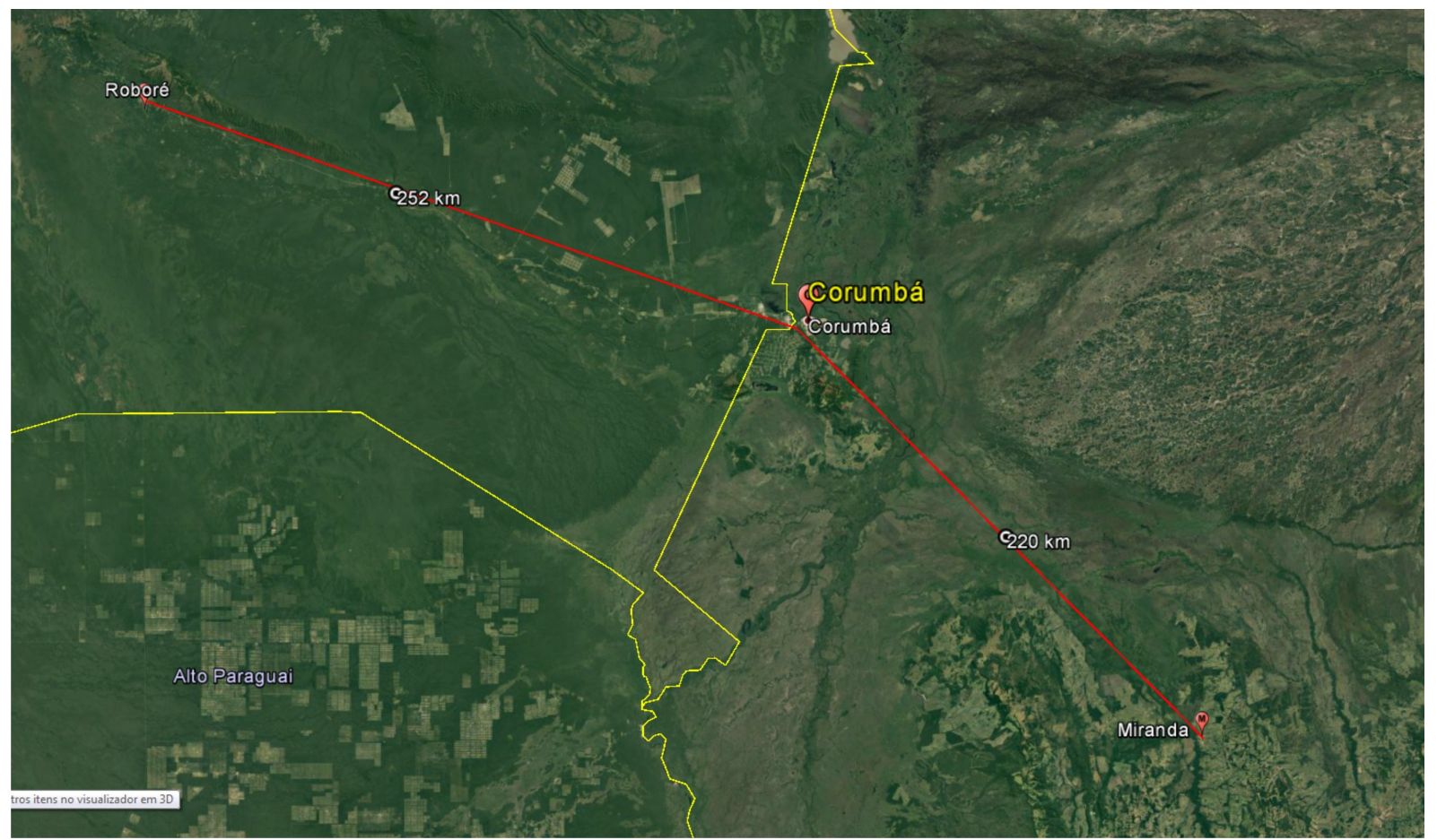


Do lado brasileiro, as linhas de abastecimento são bem mais longas, pois o Mato Grosso do Sul, especializado em produção de "commodities" produz muito pouco para o abastecimento alimentar de sua população, sendo grande importador de frutas e hortaliças.

Figura 3: Localização do Arranjo Populacional de Fronteira de Corumbá, em relação às Capitais, entrepostos de abastecimento.

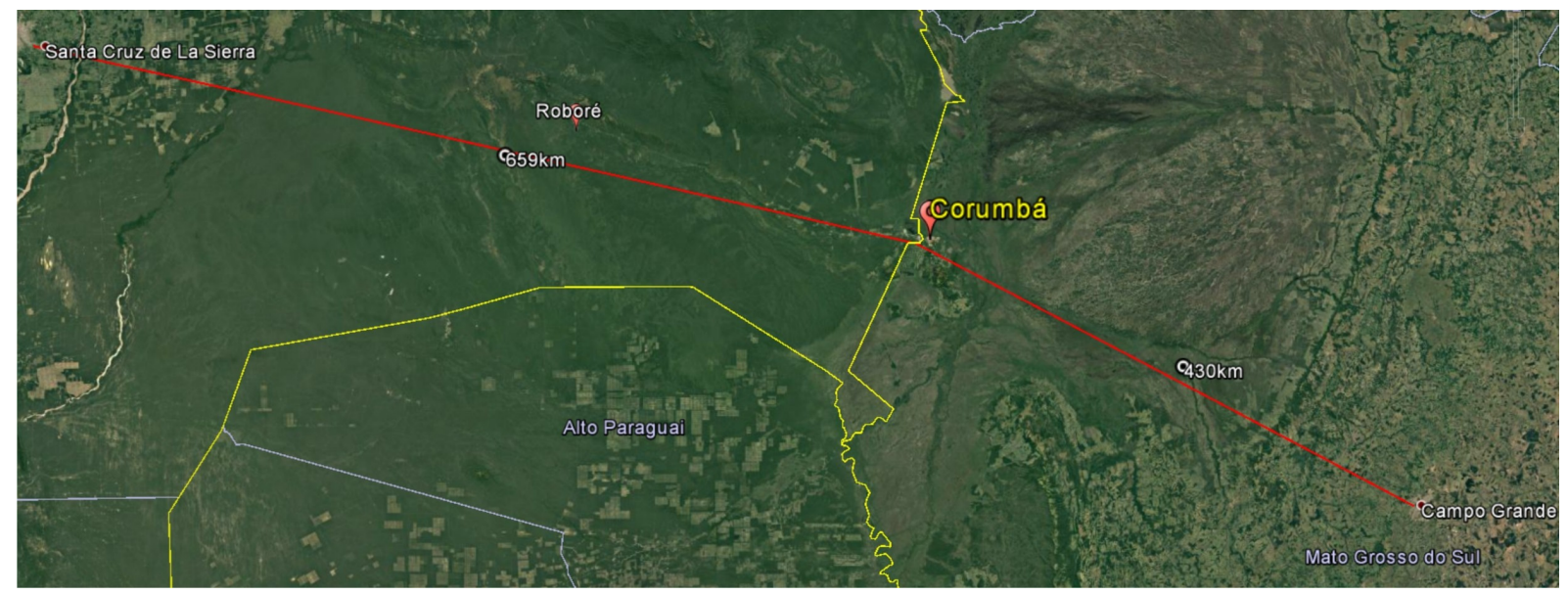

Em levantamento feito junto aos principais supermercados e ao principal atacado que fornece produtos aos feirantes e mercearias (Sacolão), mostrou que os produtos hortigranjeiros que chegam a Corumbá são provenientes do CEASA-MS de Campo Grande a $430 \mathrm{~km}$, e que por sua vez atua basicamente como entreposto de produtos provenientes de outros estados. Outros produtos são provenientes do CEAGESP de São Paulo, a 1.430 km, do CEASA-PR de Curitiba, a $1.450 \mathrm{~km}$ e de uma empresa distribuidora de hortaliças de Pato Branco, no Paraná, a $1210 \mathrm{~km}$, como é ilustrado pela Figura 4. No caso da origem dos produtos de Curitiba o proprietário do estabelecimento atacadista de Corumbá aproveita o frete de retorno de sua empresa de transportes que leva produtos a Paranaguá e no caso de Pato Branco, a matriz de uma das redes de supermercados de Corumbá se situa no Sudoeste do Paraná.

Além da distancia, o isolamento é reforçado pelas dificuldades de acesso: Enquanto Puerto Suarez além da ligação rodoviária, possui ligação ferroviária com a capital Santa Cruz de la Sierra, a única ligação rodoviária de Corumbá com o Brasil se dá através da BR 262, por onde passa todo fluxo de caminhões que abastece a região. 
Figura 4: Linhas de abastecimento alimentar do Arranjo Populacional de Fronteira de Corumbá.

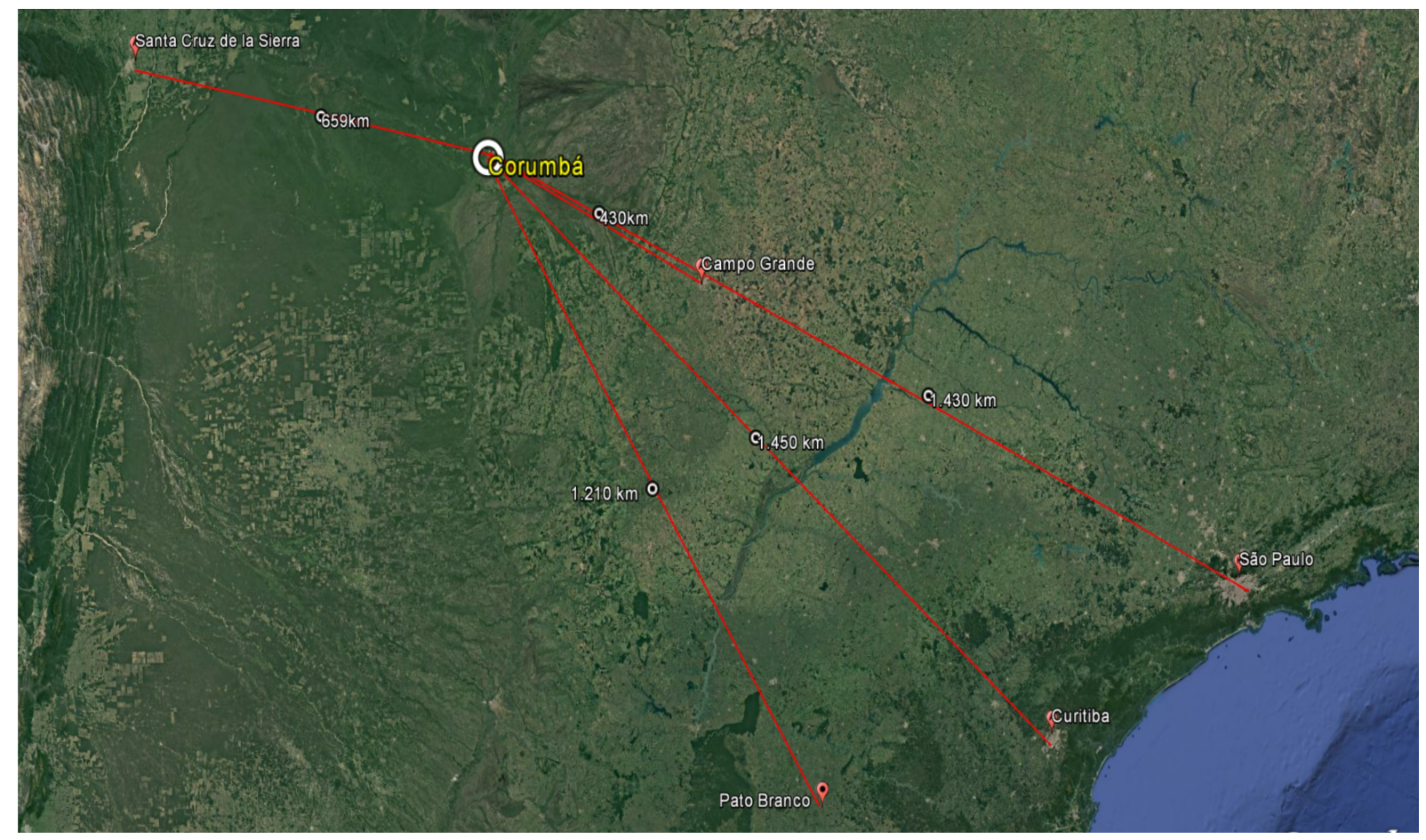

O ponto frágil desta rodovia é a ponte Poeta Manoel de Barros sobre o Rio Paraguai que é de alto risco, sujeito a acidentes com barcaças. Nos últimos anos ocorreram dois acidentes com Barcaças, na ponte, sendo que no primeiro, ocorrido em 26 de agosto de 2014, uma embarcação paraguaia atingiu um dos pilares da ponte comprometendo o transito de caminhos por vários dias (GAZETA, 2014). Em outro episódio, dia 15 de novembro de 2016 durante um temporal, a ventania soltou barcaças que estavam amarradas na margem e que atingiram um pilar da ponte (CORREIO DO ESTADO, 2016). Em ambos os casos, a ponte ficou interditada por vários dias para avaliação dos riscos, causando problemas de desabastecimento e aumento exorbitante dos preços em Corumbá.

Além disso, duas greves de caminhoneiros em 2015 , a primeira em fevereiro-março de 2015 com aproximadamente 14 dias (FOLHA, 2015) e outra em novembro de 2015 com cerca de15 dias (G1-GLOBO, 20015), novamente causaram desabastecimento na Região. Em todos esses episódios o desbastecimento só não foi maior graças aos produtos procedentes da Bolívia, que minimizaram a crise de desabastecimento. 


\section{SEMINÁRIO INTERNACIONAL DE PÓS GRADUAÇÄO EM DESENVDLVIMENTO RURAL SUSTENTÁVEL IV JORNADA QUESTÄO AGRÁRIA E DESENVOLVIMENTO \\ INTERDISCIPLINARIDADE E DESENVOLVIMENTO RURAL SUSTENTÁVEL \\ UNIOESTE - MARECHAL CÂNDIDO RONDON - PR \\ 22 A 25 DE NOVBMBRO DE 2017}

O Comercio Transfronteiriço também age como regulador de mercado, fazendo com que a Região não seja afetada pelas crises de abastecimento do Brasil e vice versa. Como exemplos temos a crise do tomate de 2012 quando este aumentou $200 \%$ (G1-GLOBO, 2012) e a crise do feijão de 2016 (CORREIO POPULAR, 2016), que causaram explosão de preços e até desabastecimento destes produtos no Brasil, e que não foram sentidos na região.

Assim, a integração comercial entre as cidades bolivianas e brasileiras neste Arranjo Populacional de Fronteira é fundamental para o abastecimento e segurança alimentar da população dos dois países, para garantir o abastecimento em caso de interrupção do tráfico de caminhões e regulagem de preços em momentos de crise.

Apesar da aparente oposição entre agricultores e feirantes bolivianos e brasileiros, relatados por Souza (2010) e Cuyate (2015), na prática se observa que há um intenso intercambio entre os agricultores e feirantes dos dois países, como relataram Costa et. al. (2008 e 2009).

Tanto os feirantes bolivianos compram dos agricultores brasileiros como estes compram dos feirantes bolivianos e vice versa, dependendo da disponibilidade de produtos e dos preços. Assim como chegam produtos dos agricultores bolivianos ao Brasil, também os produtos brasileiros chegam à Bolívia. No entanto, como o mercado brasileiro é maior que o boliviano, isto poderia aumentar a vantagem para os agricultores bolivianos, mas isso só seria valido se todo o mercado fosse atendido por produtos locais.

As dinâmicas feitas junto com olericultores bolivianos mostram que eles são mais organizados, mais especializados, e em sua quase totalidade vendem seus produtos a atravessadores que vem buscar o produto na propriedade. Produzem basicamente alface, cebolinha, couve, salsa e tomate, produtos mais valorizados, e com exceção do tomate, mais fáceis e rápidos de serem produzidos. De maneira geral se aproximam muito mais da lógica empresarial que os agricultores brasileiros.

Já os agricultores brasileiros apresentam um perfil mais diversificado, não estão organizados, existem desde os mais especializados até os mais diversificados, os que vendem diretamente na feira, de casa em casa, os que vendem na feira e para terceiros (feirantes ou estabelecimentos comerciais) e os que somente vendem para terceiros. Especialmente os grupos que estão em transição agroecológica tem uma preocupação maior em diversificar a sua produção e atuam com uma logica mais próxima da lógica camponesa, preferindo a estabilidade ao lucro imediato. 


\section{SEMINÁRIO INTERNACIONAL DE PÓS GRADUAÇÄO EM DESENVDLVIMENTO RURAL SUSTENTÁVEL IV JORNADA QUESTÄO AGRÁRIA E DESENVOLVIMENTO \\ INTERDISCIPLINARIDADE E DESENVIVIIMENTO RURal SUSTENTÁvel. \\ UNIOESTE - MARECHAL CÂNDIDO RONDON - PR \\ 22 A 25 DE NOVBMBRO DE 2017}

O levantamento feito junto aos feirantes bolivianos mostrou que a origem dos produtos que vendem é a mais diversificada possível e a escolha da procedência depende das condições de mercado. Assim as hortaliças folhosas são adquiridas no mercado regional, tanto no Brasil como na Bolívia, de acordo com o preço e a disponibilidade e a qualidade. Nas épocas em que não há produção local, estes podem vir de Santa Cruz ou são adquiridos nos sacolões de Corumbá, de acordo com o preço e qualidade.

Com relação às outras hortaliças, para as quais não há produção local ou esta é incipiente, há uma diferenciação de origem de acordo com a disponibilidade dos mercados: Batata, tomate, cebola branca, abóbora, repolho, pimentão, maçã, banana comum, berinjela, vagem, cenoura, chuchu, abacaxi perola, melão, em geral são adquiridos nos sacolões do Brasil, a menos que o preço seja mais barato na Bolívia. Já produtos com cebola roxa, alho, banana da terra, uva, morango, couve-flor, brócoli, melão caipira, abacaxi "santa cruz", em geral vem da Bolívia, onde há maior disponibilidade, mas se o produto for encontrado no mercado brasileiro por preço menor será adquirido aqui.

Caso interessante se dá com o mercado de grãos: No mercado brasileiro praticamente somente são encontrados o feijão carioca e o feijão preto, sendo que os feirantes compram onde for mais barato. Já produtos como ervilha, lentilha, grão de bico, quinoa, fava, vários tipos de amendoim, feijão de corda também com diferentes variedades, feijão branco e uma grande diversidade de feijões coloridos são procedentes de Santa Cruz de La Sierra. Aliás um dos pontos altos dos feirantes bolivianos é a grande diversidade de feijões, tanto do feijão comum, como de feijão de corda e também de amendoim. No entanto, nos últimos anos esta diversidade também está diminuindo, mostrando que a erosão genética também está atingindo os camponeses bolivianos,

Apesar da importância que os feirantes bolivianos tem para o abastecimento alimentar da população de Corumbá e Ladário, os conflitos continuam existindo e de tempos em tempos aparecem discursos desqualificando os produtos bolivianos e inclusive pedindo a proibição da entrada de produtos bolivianos no Brasil. Além dos problemas levantados por Souza (2010) e Cuyate (2015) de desvantagem competitiva dos agricultores brasileiros, já discutidos na introdução, alguns outros problemas eventualmente são levantados para justificar uma eventual proibição da entrada de produtos bolivianos no Brasil 


\section{SEMINÁRIO INTERNACIONAL DE PÓS GRADUAÇĀO EM DESENVDLVIMENTO RURAL SUSTENTÁVEL IV JORNADA QUESTÄO AGRÁRIA E DESENVOLVIMENTO \\ INTERDISCIPLINARIDADE E DESENVIVIIMENTO RURal SUSTENTÁvel. \\ UNIOESTE - MARECHAL CÂNDIDO RONDON - PR \\ 22 A 25 DE NOVBMBRO DE 2017}

A próprias autoras (SOUZA 2010, CUYATE, 2015) levantam a questão do uso indiscriminado de agrotóxicos na Bolívia, à qual contrapõem que no Brasil existe uma legislação que proíbe ou regula o uso dos agrotóxicos enquanto que a legislação é nova e pouco divulgada entre os horticultores. No entanto embora do lado brasileiro haja grupos de agricultores em processo de transição Agroecológica (FEIDEN et. al, 2007; 2016a e b; CAMPOLIN et al.. 2010), boa parte dos agricultores assentados produz no sistema convencional, e como não há um comercio legalizado de agrotóxicos no lado brasileiro, acaba comprando os produtos na Bolívia, também sem orientação técnica.

Quanto à questão da orientação sobre o uso de agrotóxicos, atualmente se vê uma preocupação muito forte das autoridades departamentais e municipais da Bolívia em relação à orientação dos agricultores bolivianos em relação à redução do uso destes produtos e inclusive quanto à transição agroecológica, com uma série de eventos e capacitações, envolvendo inclusive técnicos brasileiros. Enquanto que no Brasil, este atendimento é dado apenas a grupos específicos e do ponto de vista institucional está havendo um verdadeiro desmonte das estruturas regulatórias deste produtos, como os cortes de recursos dos organismos regulatórios e as iniciativas legislativas de desregulamentação da legislação de agrotóxicos.

Outro fator comumente levantado é em relação à higiene na produção e lavagem. Este é um problema real, porém afeta os dois lados da fronteira e também neste caso há um processo de orientação dos agricultores ocorrendo na Bolívia e com muito menor intensidade e de forma mais localizada a alguns grupos no Brasil.

Do ponto de vista legal há um enorme problema, que é a entrada de produtos estrangeiros no país absolutamente sem nenhuma fiscalização, o que pode provocar a entrada de pragas e doenças vegetais inexistentes no país, além de que os produtos podem estar contaminados com agrotóxicos e patógenos. No entanto as normas legais atualmente em vigor tanto no Brasil, como na Bolívia foram criadas para disciplinar a importação de quaisquer produtos por empresas importadoras, o que praticamente impede o acesso de agricultores familiares ao mercado de importação e exportação de produtos alimentícios. O que torna difícil legalizar essa importação dentro dos marcos atuais. Assim é fundamental que sejam aprofundados estudos para definição de normas legais para casos específicos de Arranjos Populacionais de Fronteira, principalmente onde onde há forte dependência entre as populações dos países vizinhos. Estas normas devem sim garantir a qualidade sanitária dos 
produtos importados, mas não podem ter o objetivo de se transformar em barreiras para impedir o intercâmbio.

\section{CONCLUSÕES.}

As informações coletadas neste trabalho mostram uma grande interdependência entre as populações de Corumba e Ladário e as populações de Puerto Quijarro e Puerto Suarez, principalmente em relação ao abastecimento e segurança alimentar, devido ao isolamento das comunidades do restante do território povoado dos dois países.

A passagem de produtos pela fronteira sem nenhum controle tem um potencial de acarretar riscos para as populações, tais como contaminação com agrotóxicos ou contaminantes biológicos, porém este risco ocorre não apenas com os produtos bolivianos, mas os mesmos riscos se aplicam também aos produtos brasileiros.

É necessário e urgente fazer uma discussão profunda e bem embasada para promover a regularização do intercambio de produtos através da fronteira, mas essa regularização exige que se trabalhe em novos marcos legais específicos para situações de fronteira, pois não é possível dentro dos marcos atuais, pois estes não froam feitos para as realidades de fronteiras e muito menos para agricultores familiares.

Em geral soluções imediatistas e aparentemente fáceis de serem implementadas podem ser extremamente contraproducentes e criar problemas sérios de abastecimento.

\section{REFERÊNCIAS BIBLIOGRÁFICAS}

CAMPOLIN, Aldalgiza Inês; FEIDEN, Alberto; LISITA, Frederico Olivieri; COSTA, Mirane dos Santos, (2010) Caracterização do sistema de olericultura para transição agroecológica: potencial para geração de renda e segurança alimentar em assentamentos da reforma agrária no Pantanal, Cadernos de Agroecologia, 5(1)009-1-5, 2010, disponível em: https:/ainfo.cnptia.embrapa.br/digital/bitstream/item/25114/1/sp17332.pdf acessado em 21 de outubro de 2017, 
CAMPOLIN, Aldalgiza Ines; FEIDEN, Alberto e LISITA, Frederico Olivieri, Monitoramento socioeconômico dos Assentamentos Mato Grande, Taquaral, Paiolzinho e Tamarineiro II, Corumbá, MS: 2005 a 2011, Corumbá : Embrapa Pantanal, 2016, 25 p. (Documentos / Embrapa Pantanal, 144). Disponível em: https://www.embrapa.br/busca-depublicacoes/-/publicacao/1066330/monitoramento-socioeconomico-dos-assentamentos-matogrande-taquaral-paiolzinho-e-tamarineiro-ii-corumba-ms-2005-a-2011, acessado em 21 de outubro de 2017.

CORRÊA, Valmir Batista, (2012). A chegada do $10^{\circ}$ Trem a Corumbá foi em 1952, Correio de Corumbá.com.br, 29 de Setembro, disponível em http://www.correiodecorumba.com.br/? $\mathrm{s}=$ noticia\&id=7133, acessado em 21 de outubro e 2017.

CORREIO DO ESTADO, Ventania solta barcaças que atingem ponte sobre Rio Paraguai: Marinha vai abrir inquérito para apurar circunstâncias do acidente, Jornal Correio do Estado, 16 de novembro de 2016, disponível em: http://www.correiodoestado.com.br/cidades/corumba/ventania-faz-com-que-barcacas-sesoltem-e-atinjam-ponte-sobre-rio/291379/ acesso em 21 de outubro de 2017.

CORREIO POPULAR, Preço do feijão dispara e quilo chega a R\$ 16,00, Jornal Correio Popular, $16 / 06 / 16$, disponível em http://correio.rac.com.br/_conteudo/2016/06/campinas_e_rmc/433888-preco-do-feijaodispara-e-quilo-chega-a-r-16-em-campinas.html acesso em 21 de outubro de 2017.

COSTA, Mirane dos Santos; BRASIL, Marivaine da Silva; FEIDEN, Alberto; CAMPOLIN, Aldalgiza Inês (2008). Perfil socioeconômico de feirantes brasileiros e bolivianos que comercializam hortaliças folhosas em feiras-livres no município fronteiriço CorumbáBrasil/Bolívia, Revista Brasileira de Agroecologia - Vol. 3 - Suplemento especial, 2008, pg 41-44, disponível em https:/ainfo.cnptia.embrapa.br/digital/bitstream/item/105454/1/Perfilsocioec-feirantes-brasilenos-bolivianos.pdf acesso em 21 de outubro de 2017.

COSTA, Mirane dos Santos; BRASIL, Marivaine da Silva; FEIDEN, Alberto; CAMPOLIN, Aldalgiza Inês (2009). Do Produtor ao Consumidor: Integração Socioeconômica e Cultural em Feiras Livres na Fronteira Brasil-Bolívia; Rev. Bras. de Agroecologia, 4(2)3375-3378, 2009. Disponível em: http://aba- 
agroecologia.org.br/revistas/index.php/cad/article/view/4684/3476 acessado em 21 de outubro de 2017.

CUYATE, Rozilene, (2015), Fronteira e territorialidade dos camponeses do Assentamento 72, Ladário-MS. Dissertação de Mestrado. Universidade Federal de Mato Grosso do Sul, 2015.

IBGE (2016) Arranjos populacionais e concentrações urbanas no Brasil / IBGE, Coordenação de Geografia. - 2. ed. - Rio de Janeiro. IBGE, 2016. e-Book (PDF).

FEIDEN, Alberto; CAMPOLIN, Aldalgiza Inês; COSTA, Mirane dos S.; LISITA, Frederico O.; ANDRADE JUNIOR, Edécio Burguês de; CAVASSA, Alexandre Vasconcelos (2007). Transição agroecológica de agricultores urbanos de Corumbá, MS: caracterização preliminar dos sistemas de produção. Revista Brasileira de Agroecologia, Porto Alegre, 2(2)215-218, 2007. Edição de Resumos do V Congresso Brasileiro de Agroecologia, Guarapari, ES, out. 2007. Disponível em: http://abaagroecologia.org.br/revistas/index.php/cad/article/view/2943/2495. Acesso em: 21 outubro 2017.

FEIDEN, Alberto; JUNG, Leandro Henrique; SILVA, Márcio da; COSTA, Edgar Aparecido. (2016a) Levantamento Participativo da Produção de Hortaliças no Assentamento 72, município de Ladário-MS, colhidas e vendidas pelo Grupo Bem-Estar no ano de 2015. Cadernos de Agroecologia - ISSN 2236-7934 - V. 11, N. 2, 2016. Diponível em; http://abaagroecologia.org.br/revistas/index.php/cad/article/view/21696 acessado em 21 de outubro de 2017.

FEIDEN, Alberto; CONCEIÇÃO, Cristiano Almeida; CONCEIÇÃO, Valdinei; SILVA, Ana Maria dos Santos; BORSATO, Aurélio Vinicius. (2016b) Levantamento Participativo do Potencial de Produção de Hortaliças: Uma Ferramenta para Apoiar o Acesso a Políticas Públicas. Anais $5^{\circ}$ Seminário sobre uso e conservação do Cerrado do Sul de Mato Grosso do Sul. 15 a 17 de julho de 2016. (CD-Room).

FOLHA DE SÃO PAULO, Greve dos caminhoneiros recua após sanção de lei e passa a atingir três Estados, Jornal Folha de São Paulo, 02/03/15, Disponível em 
http://www1.folha.uol.com.br/mercado/2015/03/1596807-greve-dos-caminhoneiros-terminano-pr-mas-continua-no-rs-e-sc.shtml, acesso em 21 de outubro de 2017.

G1-GLOBO, Por causa do clima, preço do tomate dispara na região de Rio Preto, SP, Portal G1, 20/07/2012, disponível em http://g1.globo.com/sao-paulo/sao-jose-do-rio-pretoaracatuba/noticia/2012/07/por-causa-do-clima-preco-do-tomate-dispara-na-regiao-de-riopreto-sp.html, acesso em 21 de outubro de 2012.

G1-GLOBO, Caminhoneiros fazem protestos pelo país; veja a situação por estado, Portal G1, 11 de novembro de 2015, disponível em http://g1.globo.com/economia/noticia/2015/11/caminhoneiros-fazem-protestos-pelo-paisveja-situacao-por-estado.html, acesso em 21 de outubro de 2017.

GAZETA DO PANTANAL, Embarcação atinge pilar e ponte sobre rio Paraguai na região de Porto Morrinho, em Corumbá, Jornal Gazeta do Pantanal, 27/082015, Disponível em http://www.gazetadopantanal.com/2014/08/embarcacao-atinge-pilar-e-ponte-sobre-rioparaguai-na-regiao-de-porto-morrinho-em-corumba/, acesso em 21 de outubro de 2017.

ROESE, A. D., Pré-Diagnóstico da situação da horticultura em Puerto Suarez, Bolívia, Agrolink, 2003, disponível em https://www.agrolink.com.br/colunistas/coluna/prediagnostico-da-situacao-da-horticultura-em-puerto-suarez-bolivia_383819.html, baixado em 31 de outubro de 2017.

SORIANO, B. M. A. Caracterização climática de Corumbá, MS. Corumbá: EMBRAPACPAP, 1997. 25p. (EMBRAPA-CPAP. Boletim de Pesquisa, 11).

SOUZA, Sildia L. (2010). As hortaliças de origens boliviana ofertadas nas feiras livres de Corumbá: aspectos transfronteiriços. Dissertação de Mestrado. Universidade Federal de Mato Grosso do Sul, 2010.

SPERA, S. T.; TOSTÔ, S. G.; CARDOSO, E. L.; OLIVEIRA, H. de. Levantamento de reconhecimento de alta intensidade dos solos e avaliação da aptidão agrícola das terras da borda oeste do Pantanal: Maciço do Urucum e adjacências, MS. Corumbá: EMBRAPACPAP / Rio de Janeiro: EMBRAPA-CNPS, 1997. 171p. (EMBRAPA-CPAP. Boletim de Pesquisa, 9). 